\title{
The Relationship Between Physical Activity Level with Quality of Life and General Health among COVID-19 Recovered Individuals
}

Mahnaz Azmodeh

Razi University

Rastegar Hoseini ( $\square$ R.hoseini@razi.ac.ir)

Razi University https://orcid.org/0000-0001-8685-2471

Ehsan Amiri

Razi University

\section{Research}

Keywords: Exercise, Mental Health, COVID-19, Quality of Life

Posted Date: May 7th, 2021

DOl: https://doi.org/10.21203/rs.3.rs-465421/v1

License: (c) (i) This work is licensed under a Creative Commons Attribution 4.0 International License.

Read Full License

Version of Record: A version of this preprint was published at Modern Care Journal on October 3rd, 2021. See the published version at https://doi.org/10.5812/modernc.118128. 


\section{Abstract}

Background: New coronavirus (COVID-19) has a major impact on the individual's physical activity level (PAL); The COVID-19 quarantine outbreak caused a decrease in the PAL. Accordingly, it might also affect the general health and quality of life (QoL). This study aimed to evaluate the relationship between PAL with QoL and general health (GH) among COVID-19 recovered individuals (CRI).

Methods: In this descriptive-analytical study, using the multi-stage (Cluster) sampling techniques, $890 \mathrm{CRI}$ (male $(n=438)$ and female $(n=452)$ ) were volunteered from different COVID-19 testing centers in Kermanshah province. After filling out the consent form, the PAL, GH, and QoL questionnaires were completed and anthropometric parameters were measured. The PAL was assessed using the international physical activity questionnaire (IPAQ-SF), GH was assessed using the GHQ questionnaire and the QoL was measured by the QoL questionnaire (short-form-SF-12). The independent t-test was used to compare the mean of variables between men and women and the Pearson correlation coefficient test was used to evaluate the relationship between variables using SPSS software version 24 at a significant level of $(P \leq 0.05)$.

Results: The findings of the present study showed that men and women with COVID-19 had inadequate PAL (876.11 $\pm 40.23 ; 739.08 \pm 27.02)$, insufficient GH (50.13 $\pm 3.1 ; 54.15 \pm 4.28)$, and poor QoL $(22.02 \pm 2.28$; $19.23 \pm 1.87)$, respectively. The results also showed that men had significantly higher PAL $(P=0.035), G H$ $(P=0.047)$, and $Q o L(P=0.023)$ compared to women. Also, the results show that increasing the PAL improves $\mathrm{GH}$ and QoL.

Conclusions: Considering the prevalence of COVID-19 and its negative impact on GH and QoL, maintaining adequate PAL can be considered as one of the effective strategies for improving physical and $\mathrm{GH}$, and immune systems, by observing the hygiene protocol.

\section{Introduction}

After the identification of the first cases of coronavirus (COVID-19) in December 2019, the disease spread around the world quickly, leading to serious global challenges. However, none have been clinically successful, extensive efforts have been made to discover a vaccine or treatment for COVID-19. Following hygiene principles and maintaining physical distancing (social distancing) seem the best ways to prevent and control COVID-19 (1); which has caused changed behavioral patterns and impeded the daily activity habits [1]. Although these steps may be critical in reducing the prevalence of this disease, they will undoubtedly have long-term consequences on physical and general health (GH) [2,3]. These adverse health consequences are so significant that they require immediate and comprehensive efforts to prevent and counteract the side effects of the COVID-19 on the quality of life (QoL) and GH of individuals. In Kermanshah province, according to the latest updates from Kermanshah medical university (March 1 , 2016), 7,000 cases of infection, 650 dead, 6,450 COVID-19 recovered individuals (CRI). According to the results of studies, the COVID-19 severity is closely related to age and underlying diseases (hypertension, 
diabetes, cardiovascular diseases, etc.), which can quickly lead to acute respiratory distress syndrome (ARDS) $[4,5]$. Strengthening the immune system is among the approaches to prevent COVID-19 until definitive treatment is found [6]. Immune cells are easily affected by a variety of factors, including diet, hormone activity, and exercise [6, 7]. Regular exercise reduces the risk of non-communicable diseases, and viral and bacterial infections $[8,9]$. Exercise promotes persistent improvement of the immune system by creating long-term health, as well as having a profound effect on the phenotypic arrangement and functional capacity of the immune system. The reaction of almost all immune cells in the bloodstream changes during and after exercise $[10,11]$. However, impaired exercise routines, and increased stress and anxiety due to the COVID-19 outbreak, staying home restrictions, and quarantines, are not unexpected. These attenuate the immune system; reduce the QoL and GH $[12,13]$. Various measures are taken to achieve physical and $\mathrm{GH}$ and increase public health, including sports and recreational activities. Studies have shown that participating in various physical and recreational activities has physical and psychological benefits that increase the QoL $[14,15]$. According to the results of studies, a sedentary lifestyle increases the risk of developing chronic diseases such as cardiovascular disease, diabetes, and hypertension, which also increases the risk of developing COVID-19 [16, 17].

Having sufficient physical activity (PA) not only reduces the prevalence of physical illnesses, psychological disorders, and QoL, but also infectious diseases. Due to the increased prevalence of COVID-19, and the positive effect of PA on the immune system assessing the physical activity level (PAL) in CRI seems necessary. Therefore, this study aimed to investigate the relationship between PAL with QoL and GH in COVID-19 recovered individuals (CRI) in Kermanshah.

\section{Methods}

\section{Study Design}

According to the latest statistics from Kermanshah University of Medical Sciences until early February 2021, a total of 7,000 COVID-19 cases were approved by COVID-19 testing centers. For sampling, Kermanshah city was divided into 5 regions: north, south, east, west, and center. The sample size was estimated at $168 \mathrm{CRI}$ from each testing center in each region. To prevent the possible loss of sample size, 30 more CRI were considered from each region, of which a total of $990 \mathrm{CRI}$ (198 in each region) was randomly selected for the study. The selection method was based on the blocks of each area and the individuals were studied based on the random division of the blocks. After the final investigations, 100 subjects were excluded from the study due to incomplete answers to the questioners, and finally, 890 subjects (438 males and 452 females) were analyzed. Inclusion criteria included: $20-70$ years, approved COVID-19, finishing the recovery period of COVID-19 (21 days after COVID-19 test), complete improvement (having no sign or symptoms), and GH. The subjects were informed about the study, the confidentiality of the information, and the purpose of the study.

\section{Tools}


The data collection tool in this study consists of five self-reported sections from the subjects.

\section{Demographic Information}

The first section consisted of 7 questions about demographic information including age, sex, height, weight, marital status, employment status, and educational stage.

\section{COVID-19 Symptoms}

The second part was a self-assessment of COVID-19 symptoms which included 3 categories about COVID-19 symptoms based on the world health organization. The first category included questions about less-common COVID-19 symptoms: bruising and pain, sore throat, diarrhea and vomiting, swelling, headache, loss of smell or taste, skin rash, or pale fingers. The second category was related to questions about common COVID-19 symptoms: fever, dry cough, and fatigue, and the third category was related to questions about serious COVID-19 symptoms; Difficulty breathing or shortness of breath, pain or pressure on the chest, and loss of ability to move or speak.

\section{PAL}

The PAL was assessed using the short edition of the International Physical Activity Questionnaire (IPAQSF). The questionnaire was sent electronically to the T2DP and they were asked to answer all the questions carefully, giving each four days to complete the questionnaire [18]. This questionnaire consisted of 10 questions that were organized into four sections of intense PA, moderate PA, walking, and sitting [19]. The intensity and duration of PA were questioned for a week, and activities lasting more than 10 minutes were recorded $[18,19]$. Intense PA includes heavy weight training, prolonged aerobic exercise, intense cycling and running; Moderate PA includes lightweight training, regular steady-state cycling, and tennis; Walking includes walking at home, at work, leisure time walking, and planned walking; And sitting includes the amount of time you spend sitting at home, at work, leisure, reading, watching TV, and meeting friends $[20,21]$. The validity and reliability of the questionnaire for the Iranian population have been confirmed by Klishadi et al. (2007) [22]. Based on the scoring method of the IPAQ questionnaire, the individual's PAL during the past week is calculated in terms of met/minute/week; walking intensity was 3.3 METS, moderate PA 4 METS, and intense PA were considered 8 METS. To calculate the total amount of PAL, the amount of walking (METS. min. day), the amount of moderate PA (METS. min. day), and the amount of intense PA (METS. min. day) were measured during the past week [23]. The PAL scores in the range below 3000 were considered as low, between the range of 3000 to 6000 as a moderate, and above 3000 as a high PAL.

\section{QoL}

The QoL was assessed using the SF-12 that was developed as a shorter alternative to the SF-36, applicable to large-scale health surveys where the application of the longer instrument would be too timeconsuming or costly. The SF-12 has 12 questions which are grouped into 8 domains or scales of physical functioning (PF), role limitations due to physical health $(\mathrm{PH})$, bodily pain (BP), GH perception (GHP), 
social functioning (SF), role limitations due to emotional problems (RE), vitality (VT), and mental health $(\mathrm{MH})$. These 8 scales could be reduced into 2 summary components of the physical component summary (PCS) and mental component summary (MCS). The SF 12 was adapted and validated to Persian conditions by Rohani et al. [24]. The final score of the SF-12 ranged from 0-100; a higher score, indicating a better QoL.

\section{GH Questions}

The GHQ-28 questionnaire was used to assess the GH of the subjects. This questionnaire was developed in 1972 by Goldberg for screening mental disease (18). The 28-item model of this questionnaire has four subscales including physical symptoms, anxiety and insomnia, depression, and social functioning, which

is a total score of four subscales. These subscales show symptoms: however, not necessarily equivalent to psychological diagnoses (19). Numerous studies have reported good validity and reliability for this questionnaire. In Iran, the validity and reliability of this questionnaire have been confirmed $(20,21)$.

\section{Statistical analysis}

The independent t-test was used to compare the mean of variables between men and women, and the Pearson correlation coefficient test was used to evaluate the relationship between variables using SPSS software version 24 at a significant level of $(P \leq 0.05)$.

\section{Results}

The results of demographic characteristics, PAL, QoL, and GH are presented in Table 1; According to the results of the present study, the PAL, QoL, and GH in females were lower than in males (Table 1). 
Table 1

The demographic characteristics, PAL, QoL, and GH among subjects

\begin{tabular}{|c|c|c|}
\hline Variable & Male $(n=438)$ & Female $(n=452)$ \\
\hline Age (years) & $43.10 \pm 12.11$ & $41.20 \pm 9.08$ \\
\hline Height (cm) & $177.02 \pm 8.06$ & $167.01 \pm 6.04$ \\
\hline Weight (kg) & $83.01 \pm 12.02$ & $78.04 \pm 11.03$ \\
\hline $\mathrm{BMI}(\mathrm{kg} / \mathrm{m})^{2}$ & $26.49 \pm 3.03$ & $27.96 \pm 4.09$ \\
\hline PAL (MET) & $876.11 \pm 40.23$ & $739.08 \pm 27.02$ \\
\hline QoL (Score) & $22.02 \pm 2.28$ & $19.23 \pm 1.87$ \\
\hline GH (Score) & $50.13 \pm 3.11$ & $54.15 \pm 4.28$ \\
\hline Married & 357 (83.78) & $385(85.17)$ \\
\hline Single & $81(16.22)$ & $67(14.83)$ \\
\hline \multicolumn{3}{|l|}{ Education rate } \\
\hline High school & $84(19.17 \%)$ & 80 (17.70 \%) \\
\hline Diploma & $116(26.48 \%)$ & $106(23.45 \%)$ \\
\hline Associate Degree & $64(14.62 \%)$ & $66(14.61 \%)$ \\
\hline BSc & $136(31.05 \%)$ & 157 (34.74 \%) \\
\hline MSc & $33(7.54 \%)$ & $39(8.62 \%)$ \\
\hline $\mathrm{PhD}$ & $5(1.14 \%)$ & $4(0.88)$ \\
\hline \multicolumn{3}{|l|}{ Job Status } \\
\hline Employee & $173(39.49 \%)$ & $147(32.53 \%)$ \\
\hline Unemployed & $123(28.08 \%)$ & $191(42.25 \%)$ \\
\hline Student & $99(22.61 \%)$ & $82(18.14 \%)$ \\
\hline Retired & $21(4.80 \%)$ & $6(1.32 \%)$ \\
\hline Part-time & $22(5.02 \%)$ & $26(5.76 \%)$ \\
\hline
\end{tabular}

Also, Table 2 presented the frequency and percentage of symptoms in CRI in 3 categories (less-common, more-common, and serious symptoms). Based on the results, almost all subjects reported having all of the symptoms in the first (less-common symptoms; $49.09 \%$ of men and $44.25 \%$ of women) and second categories (common symptoms; $36.53 \%$ of men and $41.82 \%$ of women). while difficulty breathing was the most reported symptom in the third category (30.14\% men and $37.38 \%$ women). 
Table 2

The frequency and percentage of symptoms of COVID-19

\begin{tabular}{|lll|}
\hline Categories & Male (438) & Female (452) \\
\hline Less-common Symptoms & & \\
\hline Soreness and pain & $47(10.73 \%)$ & $55(12.17 \%)$ \\
\hline Sore throat & $40(9.13 \%)$ & $37(8.19 \%)$ \\
\hline Diarrhea and Vomiting & $24(5.47 \%)$ & $38(8.41 \%)$ \\
\hline Inflation & $8(1.82 \%)$ & $12(2.66 \%)$ \\
\hline Headache & $76(17.36 \%)$ & $79(17.47 \%)$ \\
\hline Loss of smell or taste & $21(4.80 \%)$ & $26(5.75 \%)$ \\
\hline Pimples or paleness of the fingers and toes & $7(1.60 \%)$ & $5(1.10 \%)$ \\
\hline All & $215(49.09 \%)$ & $200(44.25 \%)$ \\
\hline More-Common Symptoms & & \\
\hline Fever & $106(24.21 \%)$ & $122(26.99 \%)$ \\
\hline Dry cough & $89(20.32 \%)$ & $76(16.81 \%)$ \\
\hline Fatigue & $83(18.94 \%)$ & $65(14.38 \%)$ \\
\hline All & $160(36.53 \%)$ & $189(41.82 \%)$ \\
\hline Serious Symptoms & $132(30.14 \%)$ & $169(37.38 \%)$ \\
\hline Difficulty breathing & $69(15.75 \%)$ & $66(14.60 \%)$ \\
\hline Chest pain or pressure & $26(5.94 \%)$ & $25(5.53 \%)$ \\
\hline Losing the Ability to Move or Speak & $94(21.46 \%)$ & $89(19.70 \%)$ \\
\hline All & & $103(22.79 \%)$ \\
\hline None & & \\
\hline
\end{tabular}

The results of the present study show a significant inverse relationship between the PAL with GH and a significant positive relationship between the PAL and QoL in both men and women who recovered from COVID-19. In other words, increasing the PAL improves the GH and QoL in men and women who recovered from COVID-19 (Table 3). 
Table 3

The relationship between the PAL with QoL and GH among subjects

\begin{tabular}{|c|c|c|c|}
\hline \multirow[t]{5}{*}{ PAL } & Gender & $\mathrm{GH}$ & QoL \\
\hline & \multirow[t]{2}{*}{ Male } & $r=-0.589$ & $r=0.792$ \\
\hline & & $P=0.038$ * & $P=0.018$ * \\
\hline & \multirow[t]{2}{*}{ Female } & $r=-0.685$ & $r=0.824$ \\
\hline & & $P=0.029^{*}$ & $P=0.001$ * \\
\hline
\end{tabular}

The results of the independent t-test showed that there is a significant difference in the PAL, GH, and QoL between men and women; Men had higher PAL, GH, and QoL (Fig. 1).

\section{Discussion}

This study aimed to investigate the relationship between PAL with QoL and GH among men and women with COVID-19. The results of the present study showed that CRI had inadequate PAL and insufficient levels of $\mathrm{GH}$. The results also indicate a significant inverse relationship between the PAL and $\mathrm{GH}$ in $\mathrm{CRl}$; Considering that lower GHQ scores mean better GH. Furthermore, the results of the study showed that with increasing the PAL, GH scores decreased. According to these results, increasing the PAL among CRI can improve the $\mathrm{GH}$ of men and women through affecting $\mathrm{GH}$ components (physical symptoms, anxiety, insomnia, social dysfunction, and Depression) positively. However, our knowledge of the impact of PA on improving the $\mathrm{GH}$ of $\mathrm{CRI}$ is limited due to the novelty of the subject; However, in line with the present study, the results of studies conducted on other infectious disease showed that adequate PAL could improve the GH $[14,25]$. Besides, the results of the present study showed that COVID-19 recovered men had higher PAL than women; This might probably explain the better $\mathrm{GH}$ in men. The results also show a significant association between PAL and GH in CRI. Although the exact mechanism of exercise-induced changes in $\mathrm{GH}$ is not fully understood, the effect of exercise in promoting and enhancing $\mathrm{GH}$ is clear. The benefits of PA in improving the $\mathrm{GH}$ in $\mathrm{CRI}$ may be related to exercise-induced improvements in the immune system [26, 27]. In general, it can be concluded that maintaining PAL might have positive effects on the $\mathrm{GH}$.

Which has a profound effect on the oxidative phenotype and functional capacity of the immune system, especially in CRI with underlying diseases (e.g., type 2 diabetes, and cardiovascular disease). The alteration of almost all bloodstream immune cell behavior during and after exercise is well established (14). According to studies, the positive effect of regular exercise on chronic inflammation-related diseases is due to the reduction of abdominal fat and obesity and the subsequent anti-inflammatory effects [28]. 
On one hand, it increases the immune vaccine response, reduces the number of worn and aged $T$ cells [29], increased T cell proliferation, decreased circulating inflammatory cytokines levels, increased neutrophil phagocytic activity, increased cytotoxic activity, and increased the production of muscle cytokines such as IL-12 $[29,30]$. On the other hand, one of the theoretical models for psychosocial changes (relief or relaxation) due to PA is probably the activation of the central nervous system and the secretion of endorphins. Pierce (1999) stated that PA increases basal metabolic rate, improves blood circulation throughout the body, uses excess calories, and improves mood by releasing endorphins [31]. Also, Vickers et al (2006) believed that patients are more prone to depression that prevents them from engaging in PA [32]. Additionally, due to the widespread prevalence of COVID-19 worldwide, group PA is not possible, so $\mathrm{CRI}$ are suggested to include home-based exercise in their daily routine to improve their $\mathrm{GH}$ as well as immune system by increasing their PAL.

The results of the present study also showed a positive and significant relationship between the PAL and QoL among patients with COVID-19 (men and women). In other words, an increase in the QoL was observed with increasing the PAL in CRI. The results also showed a significant difference between QoL among men and women. In comparison to women, the higher PAL in men is probably one of the reasons for the higher QoL in COVID-19 recovered men. However, it should be noted that both COVID-19 recovered men and women had poor QoL. Consistent with the results of the present study, studies have shown that exercise increases the QoL, especially in vulnerable people [33,34]. One of the possible mechanisms of the effect of exercise on improving the QoL of CRI is to reduce stress, and anxiety [35]. Studies have shown that increasing the stress hormone levels, cortisol, in patients weakens the immune system and exacerbates anxiety and stress, and jeopardizes the recovery process, all of which reduces the QoL [36, 37]; While, exercise lowers cortisol.

\section{Conclusions}

In general, according to the studies, exercising regularly improves indicators such as stress, self-esteem, and QoL, and probably cope better with COVID-19. Low PAL may be a possible cause of COVID-19 among the subjects in the present study. Also, the low GH and QoL of CRI in the present study might be due to the increased stress and anxiety caused by COVID-19. Maintaining adequate PAL during the COVID-19 outbreak can play a preventive role. Also, the spread of the COVID-19 and the hypochondriasis have now led to higher levels of inactivity, stress, and anxiety in the community, which has reduced the MH and QoL attenuating the immune system. Therefore, exercising regularly and maintaining adequate PAL, following hygiene protocols, are among the efficient and effective approaches to increase the QoL and GH in CRI.

\section{Abbreviations}

PAL: physical activity level; QoL: quality of life; GH: general health; CRI: COVID-19 recovered individuals; IPAQ-SF: International Physical Activity Questionnaire; PCS: physical component summary; MCS:mental component summary. 


\section{Declarations}

\section{Acknowledgments}

The authors would like to thank the subjects for their willing participation in this study.

\section{Authors' contributions}

$\mathrm{RH}$ designed the study. MA experimented. $\mathrm{RH}$ analyzed the data and wrote the manuscript. EA involved in the interpretation of data, reviewed and edited the manuscript. All authors read and approved the final manuscript.

\section{Funding}

The author(s) received no specific funding for this work.

\section{Availability of data and materials}

The datasets used and/or analyzed during the current study are available from the corresponding author on reasonable request.

\section{Ethics approval and consent to participate.}

This study was approved by the ethics committee of Razi University of Kermanshah (IR.RAZI.REC.1399.064).

\section{Consent for publication}

Not applicable.

\section{Competing interests}

The authors declare no competing interests.

\section{References}

1. Grabowski D, Overgaard M, Meldgaard J, Johansen LB, Willaing I: Disrupted Self-Management and Adaption to New Diabetes Routines: A Qualitative Study of How People with Diabetes Managed Their Illness during the COVID-19 Lockdown. Diabetology 2021, 2:1-15. 
2. Vashi $Y$, Jagrit $V$, Kumar S: Understanding the $B$ and $T$ cell epitopes of spike protein of severe acute respiratory syndrome coronavirus-2: a computational way to predict the immunogens. Infection, Genetics and Evolution 2020, 84:104382.

3. Feng W, Zong W, Wang F, Ju S: Severe acute respiratory syndrome coronavirus 2 (SARS-CoV-2): a review. Molecular cancer 2020, 19:1-14.

4. Chen N, Zhou M, Dong X, Qu J, Gong F, Han Y, Qiu Y, Wang J, Liu Y, Wei Y: Epidemiological and clinical characteristics of 99 cases of 2019 novel coronavirus pneumonia in Wuhan, China: a descriptive study. The lancet 2020, 395:507-513.

5. Huang X, Wei F, Hu L, Wen L, Chen K: Epidemiology and clinical characteristics of COVID-19. Archives of Iranian medicine 2020, 23:268-271.

6. Carter SJ, Baranauskas MN, Fly AD: Considerations for obesity, vitamin $D$, and physical activity amid the COVID-19 pandemic. Obesity 2020, 28:1176-1177.

7. Al-Khami AA, Rodriguez PC, Ochoa AC: Energy metabolic pathways control the fate and function of myeloid immune cells. Journal of leukocyte biology 2017, 102:369-380.

8. Warburton DE, Bredin SS: Health benefits of physical activity: a systematic review of current systematic reviews. Current opinion in cardiology 2017, 32:541-556.

9. Pape K, Ryttergaard L, Rotevatn TA, Nielsen BJ, Torp-Pedersen C, Overgaard C, Bøggild H: Leisuretime physical activity and the risk of suspected bacterial infections. Medicine and science in sports and exercise 2016, 48:1737-1744.

10. Simpson RJ, Campbell JP, Gleeson M, Krüger K, Nieman DC, Pyne DB, Turner JE, Walsh NP: Can exercise affect immune function to increase susceptibility to infection? Exercise immunology review 2020, 26:8-22.

11. Hayes SC, Newton RU, Spence RR, Galvão DA: The Exercise and Sports Science Australia position statement: Exercise medicine in cancer management. Journal of science and medicine in sport 2019, 22:1175-1199.

12. Appleton L, Day AS: Disease-Related Knowledge in New Zealand Children with Inflammatory Bowel Disease (IBD) and Their Parents. Gastrointestinal Disorders 2021, 3:23-28.

13. Hayek S, Brinkman TM, Plana JC, Joshi VM, Leupker RV, Durand JB, Green DM, Partin RE, Santucci AK, Howell RM: Association of exercise intolerance with emotional distress, attainment of social roles, and health-related quality of life among adult survivors of childhood cancer. JAMA oncology 2020, 6:1194-1202.

14. White RL, Babic MJ, Parker PD, Lubans DR, Astell-Burt T, Lonsdale C: Domain-specific physical activity and mental health: a meta-analysis. American journal of preventive medicine 2017, 52:653666.

15. Pedersen MT, Vorup J, Nistrup A, Wikman JM, Alstrøm JM, Melcher P, Pfister GU, Bangsbo J: Effect of team sports and resistance training on physical function, quality of life, and motivation in older adults. Scandinavian journal of medicine \& science in sports 2017, 27:852-864. 
16. Cornejo-Pareja IM, Gómez-Pérez AM, Fernández-García JC, Barahona San Millan R, Aguilera Luque A, de Hollanda A, Jiménez A, Jimenez-Murcia S, Munguia L, Ortega E: Coronavirus disease 2019 (COVID-19) and obesity. Impact of obesity and its main comorbidities in the evolution of the disease. European Eating Disorders Review 2020, 28:799-815.

17. Di Castelnuovo A, Bonaccio M, Costanzo S, Gialluisi A, Antinori A, Berselli N, Blandi L, Bruno R, Cauda R, Guaraldi G: Common cardiovascular risk factors and in-hospital mortality in 3,894 patients with COVID-19: survival analysis and machine learning-based findings from the multicentre Italian CORIST Study. Nutrition, Metabolism and Cardiovascular Diseases 2020, 30:1899-1913.

18. Tran VD, Do VV, Pham NM, Nguyen CT, Xuong NT, Jancey J, Lee AH: Validity of the international physical activity questionnaire-short form for application in Asian countries: A study in Vietnam. Evaluation \& the health professions 2020, 43:105-109.

19. Motl RW, Sasaki JE, Cederberg KL, Jeng B: Validity of sitting time scores from the International Physical Activity Questionnaire-Short Form in multiple sclerosis. Rehabilitation psychology 2019, 64:463.

20. Ács P, Betlehem J, Oláh A, Bergier J, Melczer C, Prémusz V, Makai A: Measurement of public health benefits of physical activity: validity and reliability study of the international physical activity questionnaire in Hungary. BMC Public Health 2020, 20:1-10.

21. Lavelle G, Noorkoiv M, Theis N, Korff T, Kilbride C, Baltzopoulos V, Shortland A, Levin W, Ryan JM: Validity of the International Physical Activity Questionnaire Short Form (IPAQ-SF) as a measure of physical activity (PA) in young people with cerebral palsy: A cross-sectional study. Physiotherapy 2020, 107:209-215.

22. Kelishadi R, Ardalan G, Gheiratmand R, Gouya MM, Razaghi EM, Delavari A, Majdzadeh R, Heshmat $\mathrm{R}$, Motaghian M, Barekati $\mathrm{H}$ : Association of physical activity and dietary behaviours in relation to the body mass index in a national sample of Iranian children and adolescents: CASPIAN Study. Bulletin of the World Health Organization 2007, 85:19-26.

23. Damirchi A, Mehrabani J, Mousavi F: The relationship between obesity, overweight and demographic factors with physical activity in 18-69 year-old adults in Rasht city. Iranian Journal of Endocrinology and Metabolism 2013, 15:378-386.

24. Rohani C, Abedi HA, Langius A: The Iranian SF-12 Health Survey version 2 (SF-12v2): Factorial and convergent validity, internal Consistency and test-retest in a healthy sample. Iranian Rehabilitation Journal 2010, 8:4-14.

25. Liu H, Li F, Li J, Zhang Y: The relationships between urban parks, residents' physical activity, and mental health benefits: A case study from Beijing, China. Journal of environmental management 2017, 190:223-230.

26. Callow DD, Arnold-Nedimala NA, Jordan LS, Pena GS, Won J, Woodard JL, Smith JC: The mental health benefits of physical activity in older adults survive the COVID-19 pandemic. The American Journal of Geriatric Psychiatry 2020, 28:1046-1057. 
27. Shalash A, Roushdy T, Essam M, Fathy M, Dawood NL, Abushady EM, Elrassas H, Helmi A, Hamid E: Mental Health, Physical Activity, and Quality of Life in Parkinson's Disease During COVID-19 Pandemic. Mov Disord 2020, 35:1097-1099.

28. Petersen AMW, Pedersen BK: The anti-inflammatory effect of exercise. Journal of applied physiology 2005, 98:1154-1162.

29. Spielmann G, McFarlin BK, O'Connor DP, Smith PJ, Pircher H, Simpson RJ: Aerobic fitness is associated with lower proportions of senescent blood T-cells in man. Brain, Behavior, and Immunity 2011, 25:1521-1529.

30. Drela N, Kozdron E, Szczypiorski P: Moderate exercise may attenuate some aspects of immunosenescence. BMC geriatrics 2004, 4:1-7.

31. Peirce N: Diabetes and exercise. British journal of sports medicine 1999, 33:161-172.

32. Vickers KS, Nies MA, Patten CA, Dierkhising R, Smith SA: Patients with diabetes and depression may need additional support for exercise. American journal of health behavior 2006, 30:353-362.

33. Ross KM, Milsom VA, Rickel KA, DeBraganza N, Gibbons LM, Murawski ME, Perri MG: The contributions of weight loss and increased physical fitness to improvements in health-related quality of life. Eating behaviors 2009, 10:84-88.

34. Shin W-k, Song S, Jung S-Y, Lee E, Kim Z, Moon H-G, Noh D-Y, Lee JE: The association between physical activity and health-related quality of life among breast cancer survivors. Health and quality of life outcomes 2017, 15:1-9.

35. Morris L, Stander J, Ebrahim W, Eksteen S, Meaden OA, Ras A, Wessels A: Effect of exercise versus cognitive behavioural therapy or no intervention on anxiety, depression, fitness and quality of life in adults with previous methamphetamine dependency: a systematic review. Addiction science \& clinical practice 2018, 13:1-12.

36. Peake JM, Neubauer O, Walsh NP, Simpson RJ: Recovery of the immune system after exercise. Journal of Applied Physiology 2017, 122:1077-1087.

37. Jesus I, Vanhee V, Deramaudt TB, Bonay M: Promising effects of exercise on the cardiovascular, metabolic and immune system during COVID-19 period. Journal of Human Hypertension 2021, 35:13.

\section{Figures}


Male $\square$ Female

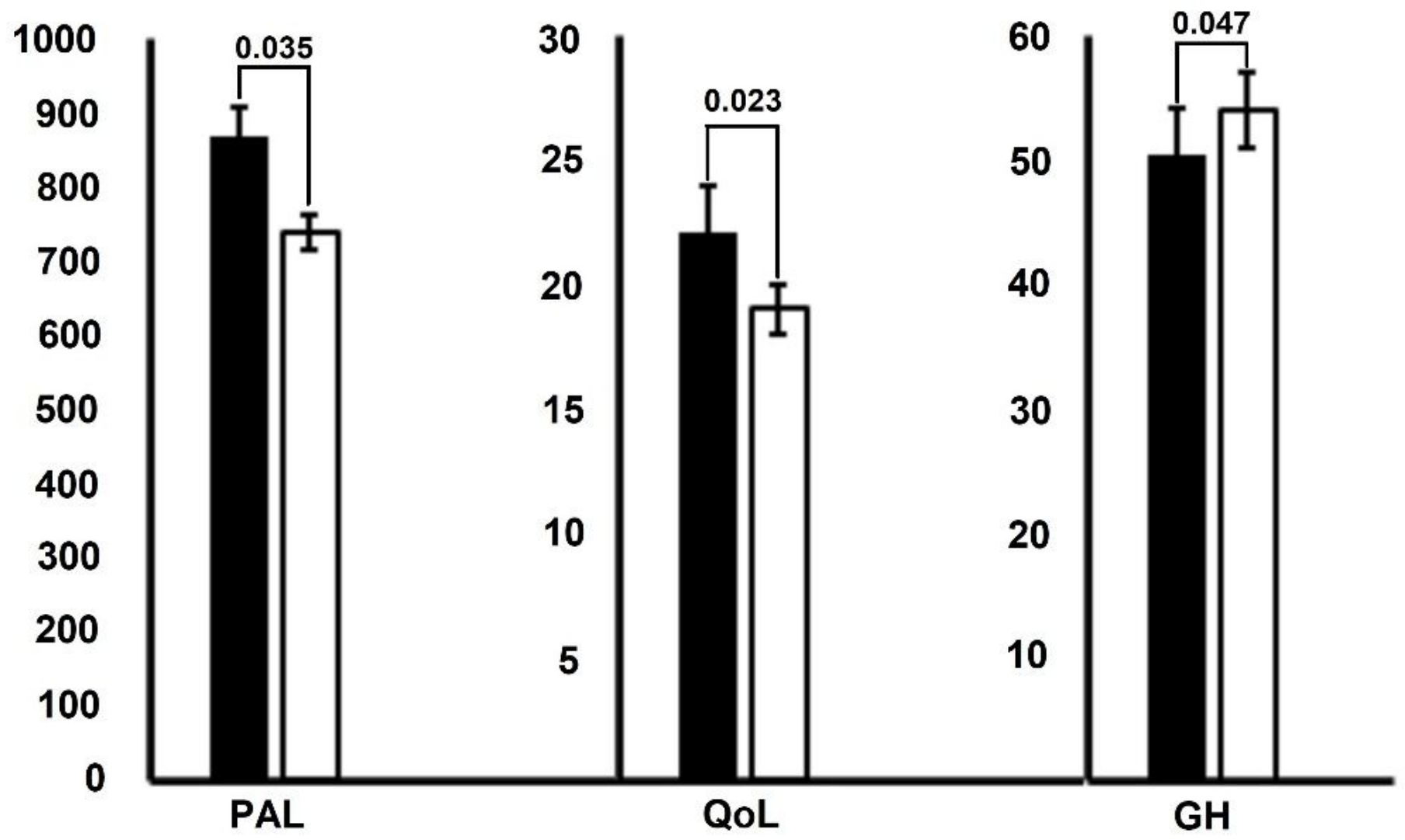

Figure 1

Comparison of PAL, GH, and QoL between men and women with COVID-19. 